\title{
Journal of Obstetrics Gynecology and Reproductive Sciences
}

Abd El-Naser Abd El-Gaber Ali. J Obstetrics Gynecology and Reproductive Sciences

\section{Research Article}

Open Access \section{Preterm Labor with Short Cervix \\ Abd El-Naser Abd El-Gaber Ali ${ }^{1 *}$, Khaled M Abdallah ${ }^{2}$, Ahmed Abdelhamid ${ }^{2}$ \\ ${ }^{1}$ Department of Obstetrics \& Gynecology Departments, South Valley University, Egypt. \\ ${ }^{2}$ Department of Obstetrics \& Gynecology AL-Azhar University, Egypt.}

Sildenafil Citrate versus Nifedipine and Dydrogesreone in Prevention of

${ }^{*}$ Corresponding Author: Abd El-Naser Abd El-Gaber Ali, Obstetrics \& Gynecology Department - Faculty of Medicine- South Valley University. Email: ayman_gamal007@yahoo.com

Received date: April 28, 2018; Accepted date : May 07, 2018; Published date: May 08, 2018.

Citation this Article: Abd El-Naser Abd El-Gaber Ali, Khaled M Abdallah, Ahmed Abdelhamid, Sildenafil Citrate versus Nifedipine and Dydrogesreone in Prevention of Preterm Labor with Short Cervix J. Obstetrics Gynecology and Reproductive Sciences.

Doi: $10.31579 / 2578-8965 / 009$

Copyright @ 2018 Abd El-Naser Abd El-Gaber Ali et al. This is an open-access article distributed under the terms of the Creative Commons Attribution License, which permits unrestricted use, distribution, and reproduction in any medium, provided the original auth or and source are credited.

\begin{abstract}
:
Background

Prevention of the premature birth occurrence remains is considered one of the most tough challenges for obstetricians worldwide, mainly to avoid neonatal prematurity complications leading to short and long term morbidities additionally prematurity prevention will reduce premature neonatal mortality rates which is considered a major health concern of obstetricians, neonatologists and families.
\end{abstract}

\section{Objective}

To compare and contrast the efficacy of Sildenafil citrate, Nifedipine and Dydrogesrone in prevention of premature labor in gestations with short cervix.

\section{Setting}

Obstetrics \& Gynecology Departments, Faculties of medicine, south Valley and Al-Azhar (Asyut) Universities, Egypt.

\section{Duration}

from September 2014 to March 2018.

\section{Patients And Methds}

the study was conducted on 300 pregnant women who randomly divided into three groups: Group I included 100 cases received Sildenafil citrate (Respatio tablet $20 \mathrm{mg}$ twice daily orally), Group II included 100 cases received Nifedipine (Epilat retard tablets 20mg twice daily orally) and Group III included 100 pregnant women received dydrogesreone $10 \mathrm{mg}$ (Duphaston) twice dailyorally.

\section{Results}

incidence of preterm labor was (9.37, 8.51 and 14.28) in (Group I, Group II and Group II) respectively. Mean \pm SD of cervical length at 32 weeks of gestation was mildly statistically significant among groups ( $p$ value $<0.05$ ) but no significance in neonatal outcome ( $\mathrm{p}$ value $>0.05$ ) except birth weight which had a highly statistically significant difference $(\mathrm{p}$ value $<0.001)$. There was a highly statistically significant difference among studied groups as regard to drug side effects in ( $\mathrm{p}$ value $<0.001$ ).

\section{Conclusions}

Sildenafil citrate was as effective as Nifedipine and better than oral Dydrogesterone on myometrial relaxation and prevention of preterm birth in pregnant women who had short cervix.

\section{Reccommendation}

Sildenafil citrate could be one of the most successful agents in prevention of preterm labor in threatened preterm cases.

\section{Keywords}

Sildenafil citrate - Nifedipine - Dydrogesrone - Preterm labor - Short cervix 


\section{Introduction}

Preterm labor is defined as delivery of fetus after 20 weeks and less than 37 completed gestational weeks. Preterm birth is always a major obstetric healthcare issue worldwide ${ }^{[1,2]}$. It represents a major cause of neonatal, infant and child death and disability up to age of 5 years in the developed world and represents the leading cause of perinatal mortality and morbidity in the whole world ${ }^{[3 \& 4]}$, about fifteen million premature neonates are born every year globally, and a million of them die because of prematurity complications ${ }^{[4,5]}$. Preterm babies are at greater risks of grave perinatal morbidities ${ }^{[6,8]}$. Although many babies delivered prematurely had a normal and completely healthy life, some significant proportion experienced life-long disabilities and health issues ${ }^{[9]}$. The chief dilemma of premature births is its negative impact on neonates themselves, their families, and society as a whole in which there is significant healthcare costs due to perinatal health issues and long term disabilities ${ }^{[1,4,7,10]}$. Prevention of preterm labor has the priority in health care system programs since preventive measures are superior than treatment protocols ${ }^{[11]}$.

Prevention of preterm labor to be successful requires multiple approaches including public health efforts with educational health programs, modification of patient lifestyle, optimal obstetric protocols of healthcare, efficient approaches for prediction and diagnosis of threatened and established preterm labor and implementation of effective, tailored case management pathways according to case scienario ${ }^{[12]}$. Preconception intervention modalities e.g weight reduction in obese female population, nutritional supplementation for underweight women, and cessation of smoking have a favourable impact on premature birth rates and its clinical sequelae ${ }^{[13,14]}$. Dydrogesreone is a progesterone stereoisomer acts at biochemical level as a selective progestin with a high receptor affinity, due to its retro-structure that binds to the progesterone receptor. Dydrogesreone is safe and have well acceptable tolerability. It is similar to natural progesterone hormone in molecular structure and pharmacological properties with sufficient oral bioavailability. 2-5 hours is the maximum time required for Dydrogesreone to reach peak plasma concentration levels after oral intake, $20 \mathrm{mg} /$ day of Dydrogesterone is equivalent to $200 \mathrm{mg}$ of progesterone administered vaginally ${ }^{[15]}$. Nifedipine is a calcium channel blocker that could be used as an key tocolytic agent ${ }^{[16,17]}$. The most substantial updated Cochrane review ${ }^{[18]}$ concerning calcium channel blockers displays that it could be used for tocolysis in prevention of acute threatened preterm delivery according to different 12 RCTs (10 of them used Nifedipine) 1029 patients were recruited in these trials. This review had concluded that, as comparison to any other tocolytic agent (as beta-mimetic mainly), calcium channel blockers (Nifedipine mainly) could diminish the hazardous risk of premature labor within 7 days of administration. Sildenafil citrate in fact enhances smooth muscle relaxation by preventing cGMP degradation (the second messenger) by phosphodiesterase enzyme (PDE5) ${ }^{[19,20]}$. Moreover, the BKCa channels had been implicated by direct or indirect fashion in the sildenafil mode of action ${ }^{[21,22]}$.

\section{Aim of Work}

The aim of this research study is to compare the effectiveness of different tocolytic agents (Sildenafil citrate, Nifedipine and Dydrogesreone) in prevention of premature labor in gestations with short cervix.

\section{Patients and Methods}

The study was performed on 300 gestations from those visitingto Obs fetal medicine units of Obstetrics \& Gynecology departments at South valley and AlAzhar (Asyut) University Hospitals in the period from September 2014 to March 2018. Inclusive research criteria; 19 - 40 years old, BMI $<30 \mathrm{~kg} / \mathrm{m} 2$, mid-gestation (20-24 weeks), normal fetal growth pattern, short cervical length (20 mm or less), singleton gestation. Exclusive research criteria; painful regular progressive uterine contractions, prior history of premature labor, polyhydramnios, presence of rupture membranes, presence of cervical cerclage, major congenital fetal malformations, chronic maternal diseases: e.g diabetes, hypertension, cardiac or renal disorders.
A written informed consent was obtained from all recruited subjects for the research study according to medical ethics committee of South valley and AlAzhar universities. The recruited gestations were randomly allocated equally into three research groups: group I included 100 cases received Sildenafil citrate (Respatio tablet $20 \mathrm{mg}$ twice daily orally), group II included 100 cases received Nifedipine (Epilat retard tablets $20 \mathrm{mg}$ twice daily orally) and group III included 100 pregnant women received oral Dydrogesterone $10 \mathrm{mg}$ (Duphaston) twice daily orally. To fulfill the target number of cases for this study (300 cases), we actually examined about 5000 pregnant women at mid-gestation.

Methods: (1) Full clinical history taking including meticulous menstrual history for precise estimation of expected date of delivery (2) Full clinical physical examination and assesment, involving general, obstetric and local examinations (3) laboratory investigations e.g CBC, RBS, kidney and liver function tests (4) Sonographic examination and assesment: (a) Trans-abdominal sonography for fetal biometry (including BPD, HC, FL and AC), placental site and grading, amniotic fluid volume, fetal anomalies (b) Trans-vaginal sonography for cervical length (CL) measurement (at 24, 28 and 32 weeks of gestation).

\section{Randomization and Blinding:}

Recruited subjects were allocated randomly into 3 research groups by using a computer-generated randomization system (Microsoft office excels, 2010). The randomization list was hidden, expressed by sequential numbers and sealed in opaque envelopes just before start of allocation. Each number was linked to a ready prepared pack which contained sildenafil citrate (Respatio 20mg), calcium channel blocker (Epilat retard $20 \mathrm{mg}$ ) or Dydrogesterone (Duphaston 10mg). The process of packing, numbering and sealing were performed by 2 different persons other than the investigator. Both investigator and observer were not aware about which drug cases had received (double-blinding).

\section{Follow up}

(a) All patients were followed up every two weeks until time of delivery and for one week later (b) Any episodes of premature labor contractions were clinically assessed carefully and recorded (c) If manifestations of threatened preterm labor progressed and not controlled with the regimen in this study, the patients were admitted to the hospital and magnesium sulphate in intravenous drip was commenced in a dose of $6 \mathrm{~g}$ in $500 \mathrm{ml}$ glucose 5\% and repeated every 6 hours till premature uterine contractions have resolved (d) Any complications developed were recorded. During follow up 12 cases dropped from the study (4 cases in group I, 6 cases in group II and 2 cases in group III) due to difficult communications or departure outside the area of study so the final number of cases continued in the study was 288 cases that delivered at South Valley and $\mathrm{Al}$ Azhar universities hospitals. Data of all patients finally was collected, tabulated and statistically analyzed.

\section{Statistical analysis}

Data management and analysis were performed using Sigma Stat program; version 3.5 The Figures were done using Microsoft Excel. Data were statistically described in terms, mean \pm standard deviation $( \pm \mathrm{SD})$ or number and percentage. Comparisons between categorical variables were done by the chisquare test. P-values was considered significant if $<0.05$.

\section{RESULTS}

Incidence of preterm labor was (9.37, 8.51 and 14.28) in (Group I, Group II and Group II) respectively (table 3 ). Mean \pm SD of cervical length at 32 weeks of gestation was statistically significant among studied groups with $\mathrm{p}$ value $>0.05$ (table 2 ). There was a highly statistically significant difference among the 3 groups in birth weight with $\mathrm{p}$ value $<0.001$ (figure 1 ) but there was no statistically significant differences as regards TTN, RD, NICU or neonatal death (figure 2) with $\mathrm{p}$ value $>0.05$. There was a highly statistically significant difference among studied groups in drugs side effects as headache, hot flushes and palpitations with $\mathrm{p}$ value $<0.001$ (figure 3 ). 


\begin{tabular}{||l|c|c|c|c|c||}
\hline & $\begin{array}{c}\text { Group I } \\
\text { (Sildenafil citrate } \\
\text { N=100 }\end{array}$ & $\begin{array}{c}\text { Group II } \\
\text { (Nifedipine) } \\
\text { N=100 }\end{array}$ & $\begin{array}{c}\text { Group III (Dydrogesterone) } \\
\text { N=100 }\end{array}$ & \multicolumn{2}{|c|}{ ANOVA } \\
\cline { 3 - 6 } & & $25.03 \pm 6.50$ & $27.23 \pm 6.05$ & $27.86 \pm 7.54$ & 1.466 \\
\hline $\begin{array}{l}\text { Maternal age in years (Mean } \pm \\
\text { SD) }\end{array}$ & $25.46 \pm 2.65$ & $24.84 \pm 2.73$ & $25.56 \pm 3.20$ & 0.237 \\
\hline BMI in kg/m2 (Mean \pm SD) & $1.60 \pm 1.79$ & $1.83 \pm 1.96$ & $1.53 \pm 1.96$ & 0.147 \\
\hline Parity (Mean \pm SD) & & & 0.874 \\
\hline
\end{tabular}

Table (1): Demographics data of the 3 studied groups

\begin{tabular}{|c|c|c|c|c|c|}
\hline & \multirow{2}{*}{$\begin{array}{c}\text { Group I } \\
\text { (Sildenafil citrate ) } \\
\mathrm{N}=100\end{array}$} & \multirow{2}{*}{$\begin{array}{l}\text { Group II } \\
\text { (Nifedipine) } \\
\mathrm{N}=100\end{array}$} & \multirow{2}{*}{$\begin{array}{c}\text { Group III (Dydrogesterone) } \\
\qquad \mathrm{N}=100\end{array}$} & \multicolumn{2}{|c|}{ ANOVA } \\
\hline & & & & $\mathbf{F}$ & P-value \\
\hline $\begin{array}{l}\text { Cervical length at } 24 \text { weeks } \\
(\mathrm{mm})(\text { Mean } \pm \text { SD) }\end{array}$ & $14.96 \pm 2.15$ & $14.96 \pm 2.44$ & $15.80 \pm 3.38$ & 0.943 & 0.393 \\
\hline $\begin{array}{l}\text { Cervical length at } 28 \text { weeks } \\
(\mathrm{mm})(\text { Mean } \pm \text { SD })\end{array}$ & $13.13 \pm 2.09$ & $12.70 \pm 2.26$ & $12.26 \pm 4.37$ & 0.591 & 0.556 \\
\hline $\begin{array}{l}\text { Cervical length at } 32 \text { weeks } \\
(\mathrm{mm})(\text { Mean } \pm \text { SD })\end{array}$ & $12.60 \pm 1.75$ & $12.57 \pm 2.24$ & $11.03 \pm 2.29$ & 4.231 & $0.019^{*}$ \\
\hline
\end{tabular}

* statistically significant

Table (2): Comparison between the 3 research study groups concerning cervical length measurement at 24, 28 and 32 gestational weeks

\begin{tabular}{|c|c|c|c|c|c|}
\hline \multirow{2}{*}{\multicolumn{2}{|c|}{ Gestational age }} & \multicolumn{4}{|c|}{ Studied Groups } \\
\hline & & $\begin{array}{c}\text { Group I (Sildenafil } \\
\text { citrate) }\end{array}$ & Group II (Nifedipine) & $\begin{array}{c}\text { Group III } \\
\text { (Dydrogesterone) }\end{array}$ & Total \\
\hline \multirow{2}{*}{ < 37weeks } & $\mathrm{N}$ & 9 & 8 & 14 & 31 \\
\hline & $\%$ & $9.37 \%$ & $8.51 \%$ & $14.28 \%$ & $10.72 \%$ \\
\hline \multirow[t]{2}{*}{$\geq 37$ weeks } & $\mathrm{N}$ & 87 & 86 & 84 & 66 \\
\hline & $\%$ & $90.63 \%$ & $91.49 \%$ & $85.72 \%$ & $89.28 \%$ \\
\hline \multirow{2}{*}{ Total } & $\mathrm{N}$ & 96 & 94 & 98 & 288 \\
\hline & $\%$ & 100.00 & 100.00 & 100.00 & 100.00 \\
\hline \multirow{2}{*}{ Chi-square } & $\mathrm{X}^{2}$ & \multicolumn{4}{|c|}{6.467} \\
\hline & P-value & \multicolumn{4}{|c|}{$0.038 *$} \\
\hline
\end{tabular}

* statistically significant

Table (3): Incidence of preterm labor in the 3 studied groups

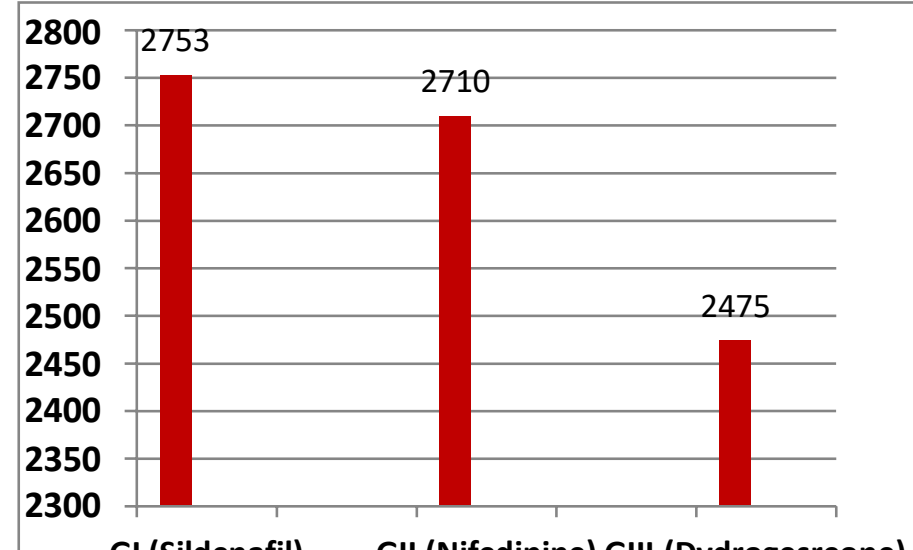

GI (Sildenafil)

GII (Nifedipine) GIII (Dydrogesreone)

Figure (1): comparison between 3 research groups as regards neonatal birth weight in grams

Auctores Publishing-Volume1-10005 www.auctoresonline.org Page-02



Figure (2): comparison between 3 research groups as regards, transient tachypnea of new born, respiratory distress, neonatal intensive care unit admission and neonatal mortalities 




Figure (3): Drugs side effects in the 3 studied research groups.

\section{Discussion}

Premature birth is one of the chief etiologies of perinatal mortality and disability in pediatric population principally correlated to the birth $<34$ gestational weeks ${ }^{[23]}$. In the current research study we investigated 3 different oral myometrial relaxing agents (Sildenafil citrate, Nifedipine and Dydrogesterone in asymptomatic gestations with short cervix which was assessed by transvaginal sonography between 20-24 gestational weeks, this current research study had displayed no statistically significant differences between the 3 research studiy groups concerning maternal age, parity or body mass index (table 1). Regarding the change in cervical length after beginning of treatment the obtained data revealed that there was statistically significant difference between research study groups in cervical length shortening with advancement of gestational period between 24 and 32 gestational weeks that was more apparent in group III (table 2), also the incidence of preterm labor was higher in group III than groups I and II (about 14\% but in groups I and group II were about (9\% and 8\% respectively) (table 3) that explained by the potency of sildenafil and Nifedipine as strong relaxant agents in uterine muscles. Birth weight in group III was statistically significantly less than that in group I and II (figure 1), but neonatal outcomes as (TTN, RD, NICU admission and neonatal deaths) in the 3 studied groups had no statistically significant differences (figure 2).

Drugs adverse effects were statistically significant among the 3 studied groups we had found that headache, palpitation and hot flushes more obvious in group I and II but less in group III (figure 3). Many previous studies had been discussed the efficacy of progesterone, calcium channel blockers or any of the other tocolytics in prevention of threatened preterm labor, from those studies, Ladan et al. ${ }^{[24]}$ studied the comparative efficiency between Nifedipine and intramuscular progesterone, the success rates with intramuscular progesterone and oral Nifedipine were $83 \%$ and $82.7 \%$, respectively but there was no a statistically significant difference in the previously mentioned 2 agents concerning the gestational age at time of delivery, mode of delivery, neonatal birth weight, in the rate of NICU admission and hospitalization period, These results and findings were in harmony with that reported in our study as regards to neonatal outcome but in our study the prevalence of preterm labor was higher in Dydrogesterone than Nifedipine this may can be explained because of the route and type of progesterone was different from that used in Ladan et al. The mechanisms of progesterone in prevention of preterm labor is by maintainance of uterine quiescence by varioust actions such as relaxation of uterine smooth muscle, blocking oxytocin action, prevention of the gap junctions formation, reducing the oxytocin receptors concentration in uterine smooth muscles and inhibiting the production of prostaglandins by amnion, chorion and decidua ${ }^{[25]}$. In a study performed by Wilasinee and Vorapong, ${ }^{[26]}$ as the study had compared oral dydrogesreone (20 $\mathrm{mg}$ daily) and placebo in a randomized double blinded controlled trial, the study results were (Rates of recurrent uterine contractions in both groups were $87.5 \%$ versus $91.7 \%$, p value was 0.64 and there were no differences in latency periods between both groups $32.7 \pm 20.2$ days versus $38.2 \pm$ 24.2 days with $p$ value was 0.39 so Wilasinee and Vorapong, study recommended that adjuvant treatment with oral Dydrogesterone 20 $\mathrm{mg} /$ day could not decline the rate of recurrent uterine contractions and prolong latency periods in preterm birth management in comparison with placebo and these findings agreed with our study results. But in another study reported by Bomba-Opon et al. [27] that was a retrospective review of usage of $200 \mathrm{mg}$ progesterone vaginally after tocolysis by fenoterol or verapamil in threatened preterm birth and had found that it was associated with prolongation of gestational period in comparison to no medication ( 7.6 versus 6.3 weeks with $p$ value was $0.039)$.

In this study we selected dydrogesterone for investigation in order to overcome the disadvantages of oral progesterone that has a wide range variability in absorption and bioavailability among different individuals. Also about the dose $20 \mathrm{mg} /$ day we had selected

because it had an equivalent dose to $200 \mathrm{mg}$ of vaginal progesterone as mentioned in Ariea et al.'s study ${ }^{[28]}$. In Systematic review and metaanalysis reported by Agustín et al. ${ }^{[29]} 26$ trials that involving 2179 women were included. Nifedipine had been associated with a significant decline in the risk of preterm labor within 7 days of starting of treatment (relative risk, 0.82; 95\% confidence interval , 0.70-.097) and < 34 weeks of gestation (relative risk, 0.77 ; $95 \%$ confidence interval 0.66 0.91 ), neonatal respiratory distress (relative risk, 0.63 ; $95 \%$ confidence interval, 0.46-0.86), In a study reported by Raheela et al. ${ }^{[30]}$ had found that, myometrial relaxation caused by sildenafil citrate was a concentration-dependent manner, the relaxation of uterine muscles in presence of $20 \mathrm{mmol} / \mathrm{L}$ of tetraethyl-ammonium was statistically significantly different ( $p$ value $<0.01$ ) than the values which were obtained with sildenafil in combination with presence of methylene blue or with 5 and $10 \mathrm{mmol} / \mathrm{L}$ tetraethyl-ammonium or sildenafil alone without any combination. In this study the systemic side effects of sildenafil citrate on mothers and possibly on fetus were considerable so if sildenafil was administered vaginally may overcome these agonizing adverse effects and that was reported by Sher and Fisch study ${ }^{[31]}$.

\section{Conclusions}

Sildenafil citrate and Nifedipine had nearly the same relaxing effect on myometrium that could prevent preterm birth in pregnant ladies with short cervix.

1) No significant differences among sildenafil, Nifedipine and Dydrogesterone as regard to neonatal outcome except birth weight, sildenafil group had a higher neonatal birth weight than Nifedipine and Dydrogesterone.

2) Headache, flushes were significance sildenafil and palpitation with Nifedipine.

\section{Recommendations}

Sildenafil citrate could be one of the most successful agents in prevention of premature labor in cases with threatened preterm labor more than Dydrogesterone with less palpitation occurrence than Nifedipine.

A future randomized controlled trial with larger sample size and Sildenafil citrate greater dosage should be used for better evaluation of the benefits and adverse effects on fetus and mothers in case of its prophylactic use in prevention of preterm labor.

\section{References}

1. Romero R, Dey SK, Fisher SJ(2014): Preterm labor: one syndrome, many causes. Science. ; 345(6198): 760-765.

2. Rubens CE, Sadovsky Y, Muglia L, et al (2014) Prevention of preterm birth: harnessing science to address the global epidemic. Sci Transl Med ; 6(262): 262sr5.

3. Lawn JE, Gravett MG, Nunes TM, et al. (2010) Global report on preterm birth and stillbirth (1 of 7): definitions, description of the burden and opportunities to improve data. BMC Pregnancy Childbirth. 2010; 10(Suppl 1): S1. 
4. Harrison MS, Goldenberg RL (2016) Global burden of prematurity. Semin Fetal Neonatal Med ; 21(2): 74-79.

5. Beck S, Wojdyla D, Say L, et al.(2010) The worldwide incidence of preterm birth: a systematic review of maternal mortality and morbidity. Bull World Health Organ.2010; 88(1): 31-38.

6. Catov JM, Scifres CM, Caritis SN, et al.(2017) Neonatal outcomes following preterm birth classified according to placental features. Am J Obstet Gynecol ; 216(4): 411.e1-411.e14.

7. Platt MJ: Outcomes in preterm infants. Public Health. 2014; 128(5): 399-403.

8. Brown HK, Speechley KN, Macnab J, et al.(2014) Neonatal morbidity associated with late preterm and early term birth: the roles of gestational age and biological determinants of preterm birth. Int J Epidemiol. ; 43(3): 802-814.

9. Shah PS, Lui K, Sj, rs G, et al. (2016) Neonatal Outcomes of Very Low Birth Weight and Very Preterm Neonates: An International Comparison. J Pediatr. ; 177: 144-152.e6.

10. Strunk T, Inder T, Wang X, Xiaoyang Wang, Carina Mallard et al.(2014) Infection-induced inflammation and cerebral injury in preterm infants. Lancet Infect Dis ; 14(8): 751-62.

11. Newnham JP, Dickinson JE, Hart RJ, Craig E. Pennell, Catherine A. Arrese et al.(2014) Strateg,ies to prevent preterm birth. Front Immunol. ; 5: 584.

12. Newnham JP, Kemp MW, White SW, Roger J. Hart Jeffrey A Keelan et al.(2017) Applying Precision Public Health to Prevent Preterm Birth. Front Public Health ; 5: 66.

13. Toivonen KI, Oinonen KA, Duchene KM (2017) Preconception health behaviours: A scoping review. Prev Med. 2017; 96: 1-15.

14. Frayne J, Hauck Y: Enjoying a healthy pregnancy: GPs' essential role in health promotion. Aust Fam Physician. 2017; 46(1): 20-5.

15. Schindler, A. E. et al. Classification and pharmacology of progestins. Maturitas. 46 Suppl 1, S7-S16 (2003)

16. Tsatsaris V, Papatsonis D, Goffinet F, Dekker G, Carbonne B. (2001)Tocolysis with nifedipine or betaadrenergic agonists: a meta-analysis. Obstet Gynecol ; 97:840-847.

17. Simhan HN, Caritis SN.(2007) Prevention of preterm delivery. N Engl J Med; 357:477-487.

18. King JF, Flenady VJ, Papatsonis DN, Dekker GA, Carbonne B. (2003) Calcium channel blockers for inhibiting preterm labour. Cochrane Database Syst Rev ; 1:CD002255.

19. Medina P, Segarra G, Torondel B, Chuan P, Domenech C,(2000) et al. Inhibition of neuroeffector transmission in human vas deferens by sildenafil. Br J Pharmacol 2000;131:871-874.

20. Archer SL.(2002) Potassium channels and erectile dysfunction. Vascul Pharmacol ;38:61-71.

21.
Bolotina VM, Najibi S, Palacino JJ, Pagano PJ, Cohen RA.(1994) Nitric oxide directly activates calcium-dependent potassium channels in vascular smooth muscle. Nature ;368:850-3.

22. Bialecki AB, Stinson-Fischer C.(1995) Kca channel antagonists reduced NO donor-mediated relaxation of vascular and tracheal smooth muscle. Am J Physiol ;268:L152-159.

23. Saigal S, Doyle LW (2008) An overview of mortality and sequelae of preterm birth from infancy to adulthood. Lancet ; 371:261-269.

24. Ladan Haghighil, Mandana Rashidi, Zahra Najmi, Homa Homam, Neda Hashemi,et al, (2017) Comparison of intramuscular progesterone with oral nifedipine for treating threatened preterm labor: A randomized controlled trial. Med J Islam Repub Iran. (6 Sep); 31-56

25. Borna, S. \& Sahabi, N. (2008) Progesterone for maintenance tocolytic therapy after threatened preterm labor: a randomized controlled trial. Aust N Z J Obstet Gynaecol. 48, 58-63.

26. Wilasinee Areeruk \& Vorapong Phupong:(2016) A randomized, double blinded, placebo controlled trial of oral dydrogesterone supplementation in the management of preterm labor. Scientific Reports| 6:20638 February|

27. Bomba-Opon, D. A.(2012). Vaginal progesterone after tocolytic therapy in threatened preterm labor. J Matern Fetal Neonatal Med. 25,1156-1159.

28. Areia, A., Fonseca, E. \& Moura, P.(2013) Progesterone use after successful treatment of threatened pre-term delivery. $J$ Obstet Gynaecol. 33, 678-681 .

29. Agustín CONDE-AGUDELO, MD, MPHa, Roberto ROMERO, MD a,b,bnc, and Juan Pedro KUSANOVIC, MD a, NIFEDIPINE FOR THE MANAGEMENT OF PRETERM LABOR: A SYSTEMATIC REVIEW AND METAANALYSIS. Am J Obstet Gynecol. 2011 February ; 204(2): 14. 3e1-134.20.

30. Raheela N. Khan, PhD, Hasiba Hamoud, MBBS, Averil Warren, MPhil, Li F. Wong, B MedSci, Sabaratnam Arulkumaran, MD, $\mathrm{PhD}$ (2004); Relaxant action of sildenafil citrate (Viagra) on human myometrium of pregnancy. American Journal of Obstetrics and Gynecology 191, 315e21.

31. Sher G, Fisch JG.(2002) Effect of vaginal sildenafil on the outcome of in vitro fertilization (IVF) after multiple IVF failures attributed to poor endometrial development. Fertil Steril ;78:1073-1076. 